\title{
Mathematics Education Students' Experiences during Lockdown: Managing Collaboration in eLearning
}

\author{
Nigel Calder *(D), Mairaj Jafri $(\mathbb{D})$ and Lina Guo \\ Te Hononga, University of Waikato, Tauranga 3243, New Zealand; mj115@students.waikato.ac.nz (M.J.); \\ educationpaiyue@gmail.com (L.G.) \\ * Correspondence: nigel.calder@waikato.ac.nz; Tel.: +64-274712262
}

\begin{abstract}
The current world crisis of COVID-19 has enforced international lockdowns in educational institutions, necessitating that these institutions quickly transition to online learning. In mathematics education studies, where collaborative problem-solving is considered a necessary pedagogical approach, lecturers have had challenges incorporating collaborative problem-solving in an authentic manner. There are now also complex living and learning contexts in which the students have to undertake their learning processes. This paper examines students' experiences of the rapid transition to online learning and their perceptions of the advantages and barriers that ensued. A small comparative case study was used to explore the complexity of the situation, within rich, authentic settings. Questionnaires and semi-structured interviews were used. The participants found that personal circumstances related to having children and partners at home while they studied, and aspects such as not interacting directly with other students to clarify and mediate their thinking, led to major initial frustrations with collaborating. While some of these continued throughout lockdown they did adjust and recognize that the advantages, such as a mix of formal and informal digital pedagogical media, gave them greater flexibility and led to deeper reflective thinking. We contend that some elements related to the adaptions made should become permanent features of face-to-face learning.
\end{abstract}

Mathematics Education Students'

Experiences during Lockdown:

Managing Collaboration in eLearning.

Educ. Sci. 2021, 11, 191. https://

doi.org/10.3390/educsci11040191

Keywords: eLearning; collaboration; problem-solving; mathematics education; student experiences; COVID-19 lockdown

Academic Editors: Liudmila Liutsko and James Albright

Received: 16 March 2021

Accepted: 16 April 2021

Published: 20 April 2021

Publisher's Note: MDPI stays neutral with regard to jurisdictional claims in published maps and institutional affiliations.

\section{Introduction}

The current world crisis of COVID-19 has enforced international lockdowns in preschool, school, and tertiary educational institutions. Tertiary education is post-secondary education such as university study. These lockdowns initiated a rapid transition in the delivery of tertiary education from a predominantly face-to-face mode of delivery to eLearning. It also provided some tertiary students with considerable challenges in managing their learning, collaboration in particular, as they became constrained to a single home environment with partners, dependents, and roommates, and the associated responsibilities, which were now part of their daily routines. This influenced their sense of wellbeing. As the crisis shifted teaching and learning online across the globe, both teachers and students have had to respond quickly to the need for creative and critical engagement through eLearning tools [1]. The urgent shift not only mandated teachers to adopt eLearning, but compelled every student and parent to use online resources and achieve goals related to work, daily life, and study [2]. With the pandemic far from over and the potential for some form of lockdown to reoccur, it is important that we gain insights into how it influences students learning and the opportunities and constraints that accompany both the lockdown and the change to eLearning. This will also be valuable as tertiary education subsequently pivots to include more digital elements in its delivery.

Mathematics teaching and learning also requires an efficient and effective pedagogical approach and design to integrate online teaching and learning environments during the 
time of the crisis. However, this unprecedented urgent demand validated pre-existing challenges related to the use of technology in mathematics education. These challenges include changing the nature of interactions between teachers and students, ways for students to collaborate, dynamic interrelations between technology and mathematics [3], and the digital competencies of teachers [3,4]. Above all, the primary concern remains: how can digital tools and technologies produce understanding and knowledge in mathematics [5]? Generally, the mathematics education community appeared to respond quickly and put forward new didactic ideas to integrate a variety of online teaching and learning solutions. During COVID-19, we (re)-discovered didactic uses of video conferencing, screen-casting, online meetings, and virtual collaboration via platforms or tools such as Zoom. Teachers who employed online tools and resources reported innovative implications for the teaching and learning of mathematics [6-8].

Although digitalization is promoted at all levels of the education system $[9,10]$, it brings both challenges and opportunities. This complexity has resulted in a slow uptake in digitalization in education [11]. However, the COVID-19 pandemic has resulted in government mandates that demand a rapid switch in the education section to digital teaching and learning. Digitalization also means that we need to consider the diversity of learners' backgrounds to achieve educational equality [12]. Previous research suggests that the digitalization of education makes the challenge of equal participation more dynamic, complex and unpredictable at all levels of the education system [13].

On the one hand, these didactic developments recommend the development of resilient online communities of inquiry (CoI) [14] and communities of practice (CoP) [15] to support the transition, while on the other, they invite researchers to critically examine these developments to identify the opportunities and constraints of transitioning to, and subsequently embedding, eLearning practices [16]. Collaborative problem-solving has been recognized as a way to facilitate thinking and understanding [17], especially in mathematics [18-20]. This study was particularly interested in students' experiences and the ways they communicated when collaboratively problem-solving through eLearning. We firstly consider how eLearning might reshape the teaching and learning experience.

\section{2. eLearning}

An online learning environment requires the active and collaborative participation of learners to explore, develop awareness, and understand the online CoI [21]. The study also found that connective technologies, including videoconferencing, have been instrumental in preserving social closeness despite social distances. They also contend that digital technologies enabled pre-service teacher collaboration, online engagement, and connection during COVID-19. The study mainly investigated the educational strategies and technologies that facilitate online learning interactions and connections. The authors redesigned course activities to suit online formats and used synchronous and asynchronous digital technologies such as mobile instant messaging (e.g., GroupMe), digital whiteboards (e.g., Padlet), and synchronous sessions (e.g., via Zoom). The results demonstrated a significant social link developed among students and teachers through collaborative strategies and resources [21].

However, Hew and Cheung [22] argued that student involvement in online discussions is still limited, with a need to increase the use and quality of online discussion in both asynchronous and synchronous settings. They used empirical evidence to identify ten main factors (Figure 1) that inhibit students' participation and knowledge construction in online collaboration and discussion. Furthermore, they proposed strategies such as the use of online scaffolds (message, sentence openers), instructor facilitation, the use of grades, posting guidelines and deadlines, and extending the duration of discussion, to address the factors that limit students' online participation in discussions [22]. 


\begin{tabular}{|c|c|c|c|c|}
\hline $\begin{array}{c}\text { Not seeing the need } \\
\text { for online } \\
\text { discussion }\end{array}$ & $\begin{array}{c}\text { Behavior or practice of } \\
\text { instructor or } \\
\text { participants }\end{array}$ & $\begin{array}{c}\text { Personality } \\
\text { traits }\end{array}$ & $\begin{array}{c}\text { Difficulty in keeping } \\
\text { up with the discussion }\end{array}$ & $\begin{array}{c}\text { Not knowing what to } \\
\text { contribute }\end{array}$ \\
\hline $\begin{array}{c}\text { Lack of critical } \\
\text { thinking skills }\end{array}$ & $\begin{array}{c}\text { Being content in } \\
\text { merely answering } \\
\text { queries }\end{array}$ & $\begin{array}{c}\text { Technical } \\
\text { aspects }\end{array}$ & Lack of time & $\begin{array}{c}\text { Not wanting to run the risk } \\
\text { of being misunderstood. }\end{array}$ \\
\hline
\end{tabular}

Figure 1. Ten factors that limit student's participation in online discussions [22].

Ervin-Kassab [23] discussed the learning management system (LMS), which she contends facilitates the co-planning and co-teaching of activities. The LMS also provides space to hold a community of practice for the guidance and professional development learning (PDL) of teachers. Other researchers have reported that online learning allows teachers to collaborate and communicate more with students and other teachers [24]. Interactions that support teachers and students to increase their capacity to (re)-invent media are an important way of developing skills of instructional design and augmenting digital literacy [25]. Others have observed that teachers proficient and confident in designing educational media experienced fewer challenges during the lockdown [26]. Schools and teachers who had previously been engaged in eLearning found the transition more seamless and were more ready and confident to teach and learn online [27].

The rapid pivoting to eLearning led to a refocusing on digital pedagogical media such as video conferencing, screen-casting, breakout rooms, screen sharing, online meetings, and virtual collaboration via platforms or tools such as Microsoft Teams and Google Classroom. Teachers who employed these online tools and resources reported some innovative implications for teaching and learning mathematics. For example, Morge [8] discovered that screen-casting and screen sharing improved inquiry and problem-solving skills. Breakout rooms were shown to improve collaborative problem-solving skills [6,7], while virtual whiteboards and slide sharing enhanced communication of mathematical thinking as students articulated creative, thoughtful learning outcomes [28]. While some of the research findings appear to apply to a range of contexts, such as Google Slides enhancing communication [28], questions still need to be examined. For instance, how might collaborative problem-solving be taught effectively when e-Learning is the medium for tertiary mathematics education? We now consider aspects of the collaborative problemsolving process.

\section{Collaborative Problem-Solving}

\subsection{Problem-Solving}

Collaborative problem-solving in mathematics education draws on the seminal work of Pólya [29] and Schoenfeld [20]. A recent study considered the mathematical problemsolving activity part of logical-mathematical intelligence [5]. This intelligence has been defined as the ability to use mathematical concepts to produce conjectures, establish proofs, and apply mathematics and mathematical data to situations and to construct arguments [30]. They further explained that basic logical-mathematical intelligence develops when an individual focuses on the patterns, symmetry, logic, and aesthetics of mathematics to solve, design, and model everyday life problems and tasks [30]. Others contend that teaching mathematical problem-solving develops 21st century skills, and hence competence in solving real-world problems [31].

When problem solving, or in extended mathematical investigation, students are essentially theorizing mathematics or creating and examining mathematical conjecture [32]. Researchers often consider mathematical conjectures as generalized statements, containing essences distilled from a number of specific examples [33]. A more advanced form of problem-solving occurs when students offer counter examples, or when they identify similarities between two mathematical explanations [34]. These often emerge through exchanges related to mathematical explanation, emphasizing the importance of collaborative 
problem-solving [34] and effective communication between collaborators. In other words, they can occur as part of a collaborative process.

\subsection{Collaborative Problem-Solving}

Studies utilizing Vygotsky's participatory perspectives of education have found that cognitive development of the learner takes place through collaboration, which involves mutual engagement, discussion, and joint decision making [35]. During collaboration, individuals might experience socio-cognitive conflict, an external process through which they receive opinions different from their own. Such conflicts can facilitate cognitive development. Barkley et al. [17], while discussing the theoretical and pedagogical rationale for collaborative learning, explained that students learn when new information complements their existing understandings, through scaffolded activities, imitating and interacting with others, and most importantly when they seek deeper understanding about a concept.

PISA [36] defines collaborative problem-solving thus: "Collaborative problem-solving competency is the capacity of an individual to effectively engage in a process whereby two or more agents attempt to solve a problem by sharing the understanding and effort required to come to a solution and pooling their knowledge, skills and efforts to reach that solution" [37] (p. 134). Furthermore, the joint coordination of a task enables students to communicate and negotiate in order to support decision-making [37]. They become involved in "a coordinated joint commitment to a shared goal" where collaboration moves beyond the sharing of ideas and task coordination to "reciprocity, mutuality and the continual (re)negotiation of meaning" [38] (p. 23).

Collaborative problem-solving in mathematics can facilitate mathematical investigation and argumentation, enhancing the consolidation of conceptual understanding [39]. Investigating mathematical problems gives students opportunities to think in creative and critical ways, and to better understand the world in which they live [18]. Collaboration with online tasks has been explored [40], but there is very little literature concerned with managing collaborative mathematical problem-solving online. The researcher tried some approaches during lockdown, and it will be valuable to examine and report student perceptions of these.

\section{Digital Technology and Problem-Solving}

The use of digital technology when students are problem-solving is particularly effective when the digital media facilitate open experimentation and stimulus for discussion [41], rather than when students just respond to onscreen prompts [42] or only learn formula and practice processes in a procedural way [43]. In such open tasks, the aspect of multi-representations and the non-judgmental nature of feedback encourage the setting of informal conjectures that encourage further collaboration [44].

Recent literature [19,45-50] concerning twenty-first-century learning approaches such as edutainment, game-based learning, eLearning, blended or flip learning, and learning using dynamic mathematical software (e.g., GeoGebra) provide evidence that digital technologies help foster not only problem-solving skills, but more advanced skills such as critical-creative thinking skills [50]. Borba et al. [51] consider that eLearning allows the development of important skills such as computational skills, independent study, searching for information, problem-solving, collaborative learning, personalization, and lifelong learning.

In a graduate course for K-8 in-service and pre-service mathematics teachers, Morge [8] found that affordances provided by encyclopedia (e.g., Wikis), online discussion walls (e.g., Padlet), small chats (tweets), emoticons, and breakout rooms (e.g., Zoom) orchestrated meaningful conversations during collaborative mathematical problem-solving activities. The research study showed that a teacher can engage participants in small and large groups for discussion and co-construct the solution of a given problem [8]. The affordances of breakout rooms make it possible for teachers and students to visit other groups synchronously and question each other, explain their reasoning, and critique the reasoning of others. 
In Australia, Symons and Pierce [52] explored the online collaborative mathematical problem-solving capabilities of primary-school students. The online collaboration offered opportunities for students to build and evaluate problem-solving, reasoning, and critical thinking skills. The study demonstrated that with the equitable integration of digital technology and effective professional learning, the affordances of Web 2.0 allow teachers to not only promote procedural fluency but also to develop students' conceptual understanding, reasoning, problem-solving, and collaborative skills. As collaboration moves towards the negotiation of ideas and decision making, digital technologies can act as a mode of reasoning in sharing and establishing shared understandings. Digital technologies might be envisaged as a tool, not just to model, explore and enact conjectures, but to open up spaces where teachers and learners engage within digital media as they collaborate and talk with each other, hence enabling learners to play and think together, and to facilitate creative thinking and the capacity for learning [53].

Mobile technologies (MTs), such as tablets and smart phones, have been used increasingly to achieve social and collaborative goals in education [54]. In particular, the ubiquitous features of MT devices enable the coordination of collaborative activities because students can move with the device to work with other students at different locations [37]. Recent literature [8,45] indicates that digital tools including online communication platforms offer problem solvers a set of affordances, which they can use to orchestrate activities (explore, (re)-construct, explain, and communicate) during collaborative mathematical problem-solving. The affordances offered by the Internet, digital gadgets, and smart devices are critical in augmenting problem solver's understanding of mathematical concepts beyond formal settings [44]. However, in intermittent and unpredictable online learning situations such as COVID-19, teachers and students' reflections are necessary to examine the efficacy of digital tools and communication platforms [55]. Such investigations need to use open-ended mathematical problems and pedagogical activities that encourage students to collaboratively create knowledge about problem-solving.

\section{Materials and Methods}

A small comparative case study [56] was used to examine three students' perceptions of their experiences as New Zealand entered a six-week lockdown and they transitioned into full eLearning. Creswell and Creswell [57] contend that a case study enables the researcher to explore the authentic dynamics of situations and people, including their motivations and reasoning. The case study researcher aims to examine the characteristics of a bounded system; in this instance, the experiences of tertiary mathematics education students. The purpose is to understand the case in depth, and in its natural setting, recognizing its complexity and its context. This was an interpretive case study interested in the participants' perceptions, and hence the contextual aspects though which these perceptions evolved. The purpose of case study research is to provide a deep description of the diverse phenomena that represent life in the bounded system [58]. These insights enable the researcher to analyze and develop insights that may apply to the wider population to which that case belongs. The research considered the research question: In what ways did the Covid-19 lockdown affect tertiary students' mathematics education learning, collaborative problem-solving in particular?

A purposive sample was used. Two students from each of the researcher's three trimester A mathematics education classes were asked if they were interested in participating in the research. These were classes that had concluded. If they were interested in being involved, an email with the information sheet and informed consent form was sent to them and they were invited to participate. They could then volunteer to be involved. The aim was to obtain at least three participants for the case study. Three students were selected because they were in three separate living arrangements, having different family circumstances with the numbers and ages of children, the employment role of their partners, and their personal work situations representing the breadth of student circumstances over the three classes. 
The participants completed a questionnaire that contained a mixture of questions to gather contextual information and open-ended questions. Additionally, they participated in an individual semi-structured interview and the checking of their transcripts. The interview took approximately 50 min with a maximum of one hour, while the checking and amending of transcripts, by each participant viewing the transcript of their interview to confirm their intended meaning, took approximately $30 \mathrm{~min}$. All participants were given pseudonyms to help maintain anonymity, with ethical approval gained from the University of Waikato Ethics Committee which was actioned reflexively through the study. The data were analyzed through thematic analysis adapted from [59]. This sixstep analysis process identified the themes that are reported in the Results section. The data of recorded interviews were transcribed, organized, and synthesized, before being coded and categorized into themes in terms of the similarities and differences to search for emerging patterns. To enhance validity, data were coded by the researchers manually with cross-coding between researchers undertaken, which also helped maintain reliability with the process.

\subsection{Participants}

The three participants for the comparative case study were drawn from two papers: one, a Masters' level Mathematics Education paper; and the other, a third-year undergraduate paper. The participants considered themselves to be competent at mathematics and confident when using it in their teaching and everyday lives. Shelley (32 years old) and Anna (36 years old) were studying the Masters' paper but had differing home situations. Shelly was working full time while living in an inner-city apartment with just her husband, while Anna lived in a medium-sized provincial city suburb with her husband and young baby. She was on maternity leave while also studying the paper. Both held similar curriculum leadership roles in their respective schools, that were in different cities. Lilly (37 years old) was in the third year of a teaching degree, studying a mathematics education paper amongst her full-year program. She lived in another provincial city with her partner and their two children. These three participants' living circumstances had similarities and differences in their contexts that provided comparisons and contrasts to identify some commonalities, as well as particular insights related to their contexts. More detail related to how their individual living circumstances influenced their transition to eLearning was revealed in the data; this (Challenges: Complications in home situation) will be reported first in the results so that subsequent discussion of the themes can be linked back to the participants' circumstances. These are also valuable data because they provide insights into the nature of the social and emotional effects of the transition into lockdown.

\subsection{Collaborative Problem-Solving Processes}

One of the classes (Lilly's) started using separate online groups to perform the collaborative problem-solving, usually within the formal eLearning media, Moodle and Zoom, but also within informal social media networks. The lecturer emphasized this aspect of working in online groups and they were encouraged to form groups informally, as well as being placed into more formal working groups by the lecturer. As well as this, the other class (Anna and Shelley's) also began an approach that started with individual engagement with the problem in the asynchronous medium with the ideas and potential solutions developing incrementally through each contribution. The first contributors to the group discussion of the problem were asked not to completely solve the problem, but to allow space for everyone to contribute some thinking. They then met via Zoom to discuss all their contributions and negotiate the solution(s) through consensus.

\section{Results}

The findings of this study revealed that the three tertiary mathematics education students experienced dramatic change during the enforced COVID-19 lockdown. This included changes to their home situation, but also in the way they engaged with the math- 
ematics education and mathematical activities through eLearning. They found it difficult to undertake any collaborative work at first, especially communicating when making sense of problems and then mediating their thinking while problem-solving through the contestation and clarification of ideas. Some of this was related to the changes in their home situations, and we will consider results related to that first. These data were important because they gave insights into the contexts in which the participants' perspectives of communicating evolved, including their perceptions of their wellbeing.

\subsection{Challenges: Complications in Home Situation}

The rapid transition into lockdown led to individual variances in living and work situations at home that influenced the nature of the online learning. This had a major impact on the working environment.

For Lilly, there was the complexity of her and her partner needing to continue working, as well as her studying, and all at home with children from previous relationships.

Lilly: So basically, what happened is when we went into lockdown. I came home with my job, my job, moved into my home, and then my partner's job moved into home. So, we had two jobs going at home, I had my study, I had my two children's schooling. And then, after three weeks we had my partner's three children as well so that was five children at times.

Lilly: Both myself and my partner were essential workers, working from home. His job being highly sensitive (Department of Corrections). Also, having an autistic daughter and the highly stressful situation of being in lockdown, and the children not having their dad assist with parenting or visiting, created confusion and distress.

For Shelley, not having children made the overall living, working, and studying in one house experience different.

Shelley: As we have a small apartment, there was only one desk space and my husband was also working from home full time. While we had access to multiple devices, desk space was shared. It became the hardest thing, or the thing that changed the most was the fact that my husband was working from home, and it became a bit of competition for space that we work in. Normally, I'm sort of studying in the evenings, but he found his work didn't finish till the evening so it was, it was kind of getting creative about where I did my study.

Shelley: I guess I was lucky though like we haven't got any kids, so you know I wasn't fighting that so much. We were really lucky with the weather too. I think if it had rained persistently and we felt like we couldn't have gone outside, that would have made a huge difference. But such beautiful weather almost every day. It wasn't hard to go out and get a bit of fresh air and, you know, walk through the park.

The complexity of the new home situations also added to the students' overall workload. They reported the effects of that extra workload.

Annie: My husband working $24 \mathrm{~h} / 7$ as a manager in kiwifruit, no grandparent help with looking after our child due to lockdown, and she gave up her daytime sleep. There was increased stress with trying to study and look after a toddler with no grandparent help. Anxiety with trying to finish Masters as it was my last paper. I found it really, really, really stressful at the time and just had no time at all.

Lillie: I had to finish this year. Yeah, though I felt like I wanted to just quit.

A feeling of determination to finish the papers was articulated. Although they all found the transition to lockdown and eLearning difficult in varying extents, they did develop inner resolve and a sense of resilience through completing their papers-often through a sense of duty or responsibility. This was commonly articulated by many students, 
although those few that had to drop out of the papers obviously would not have felt that same sense of accomplishment and development of resilience.

Lillie: My family have made sacrifices for three years. I've worked so hard that I just had to finish the year out. That it wasn't going to get in the way, (no matter) how insane it got. My home situation was the hardest part though. It's a very disheartening feeling when you reach out, especially to tutors or to the university, and through no fault of their own, they can't help you. They can't fix that situation for you.

Annie: I was thinking gosh this is so hard, how am I going to finish the paper in lockdown It was a few sleepless nights and it was the anxiety but I thought at one point I've just got to get this finished. I thought maybe I should delay this but then I thought we didn't know what was happening to COVID and so I just thought, I'm just going have to do this and get it finished.

Lilly: It's made us resilient.

While they enjoyed the advantages that digital technology offered to them, such as flexibility in a collaborative learning community with peers and lecturers, the transition to eLearning initiated a sense of anxiety and isolation. In some cases, the complexities of the changed home environment and the different self-regulated skills such as time management that were required with a fully online learning environment caused additional stress. While two indicated a clear preference for at least some face-to-face activities, they nevertheless saw some advantages of eLearning.

\section{2. eLearning Experience}

\subsubsection{The Changing Nature of the Learning}

The initial unexpected transition to eLearning was problematic for two of the students in particular. They preferred the face-to-face interaction of the physical classroom. For instance, the following data were generated in the survey sent in the early stages of lockdown.

Anna: I found it harder learning online and via Zoom.

This was also articulated in the interviews. For example:

Lilly: I found it extremely difficult and stressful changing from physical lectures to an online environment, because I enjoyed coming into the lectures. I learned better face-to-face and interacting with the students and the lecturer.

The rapidity of the transition and its enforced nature were also aspects that Anna articulated.

Anna: Suddenly it was at home on your own doing everything yourself and having to understand how to set yourself up. I found it different. I think it was probably that I missed the face-to-face contact and the interaction.

\subsubsection{Advantages of eLearning}

However, Anna did see some practical advantages in the learning going online.

Anna: The advantage was that we didn't have to come into town and deal with that traffic. Parking can be a nightmare- to get into town and find parking.

Although Shelley had some issues with negotiating workspace with her husband, this led to a change in working that she recognized as advantageous.

Shelley: I think I used my phone a lot more just to sort of access and read things simply because it was a bit easier to be sitting on the beanbag browsing something than fighting for the desk space. Yeah, so I guess I did a lot more reading, reading where I took more notes which I think is beneficial in the long run, because I wasn't reading it properly before. 
Shelley was in a situation where she had effective digital connectivity but a small living space. These influenced her experience.

Shelley: I was really lucky as far as, you know, we live in the central city. So, our wifi was good and reliable, and we already had a couple of devices in the household. I was a little bit worried about my laptop, but I also had my school laptop as a backup so I guess I'm quite privileged in that way. We were well resourced but it was just a small house on one desk-that was the most difficult part.

In the later interview data, Anna also indicated that over time she adjusted to the eLearning to some extent.

Anna: I think that the Zoom was actually quite good because we actually had more. I think he (the lecturer) added a couple more. We had quite a lot of Zoom and it was good actually because he used a good balance of having Zoom. You know I think in the future, it would actually be quite good to have a Zoom, as well as coming in, like it or not. Yeah, it actually broke it (the paper) up quite well.

They also indicated that as the paper and online learning experience progressed, they began to value the associated flexibility.

Lilly: I am now very, very confident and comfortable with learning online. Yep. And ideally, I would like to take that into my future teaching to make sure that I have a work life balance with things that can be done at home, things that don't have to be done at school. So (an advantage was) just having that flexibility of being able to do it in your own time.

Shelley also felt that the experience had enhanced her personal learning and provided some PDL.

Shelley: And it was actually quite good professional development, I guess, working out what else I could do and taking it back to my job, and thinking well you know if we're back and locked down in the future, there's another tool I've got up my sleeve that I can use. I know we had some good presentations over Zoom.

\subsubsection{Self-Regulation}

There were also data that were related to self-regulation and time management. Although, for Anna, this exacerbated her feelings of stress.

Anna: I found it hard, having to read through all the material myself and trying to understand it, when it was a stressful situation. And I just felt very alone and the anxiety levels did increase.

Lilly adapted her approach to learning at times by working collaboratively with a classmate.

Lilly: We studied together about the week prior (to an assessment). Yeah, it was good. And we did a whole day of work because we live in different towns.

All three developed ways to communicate for online collaboration, as part of the formal eLearning that the lecturer facilitated, but also through more informal media such as Messenger. The informal interaction certainly became a key element of their learning.

\subsubsection{Informal Communication}

In general, they reported in the data that they found that the informal communication was beneficial, especially between students.

Shelley: I used the Facebook page quite a bit too around the discussion, you know like, especially if you had an issue and you wanted to see if somebody else was having the same problem or to discuss the Zoom. 
Interestingly they felt that having had one face-to-face class was an advantage for the eLearning. For instance, Shelley responded in the interview.

Shelley: If you can get to know people a little bit outside of study, I think it makes it easier to connect with them online.

This also helped to facilitate a more relational type of interaction, where instead of focusing on the paper's content, they would concentrate more on how they were feeling and how they were managing: their emotional wellbeing.

Shelley: I think a lot of the discussion, perhaps in previous years, might have been about the paper but this time it was more kind of a bit of a debrief about the day or the week, more so than the content of the paper. We didn't need to discuss the study, because we actually needed the support or the empathy from each other, you know, we were going through the same thing.

Lilly: We probably had more leaning on each other. We lean on each other because it was so stressful it was like okay this is how I'm feeling, anyone else feeling like this. You know, am I overreacting? Am I stressing about nothing? Can somebody put this into perspective for me? And they couldn't because they were drowning as well. They feeling like how do we do this; how do we actually do this.

Both the informal student interactions and changing the nature of the lecturer interactions to be more informal were considered to be critical to maintaining engagement.

Lilly: Because if we didn't have those communications, we didn't have like the Google chats, or the Messenger chats, or the class or individual Zoom chats. I would feel very alone. Yeah, thanks. I probably, I probably would have just flagged this paper and gone.

Annie: And I think the Zoom meetings were really supportive and we all just knew we had to be together and get through it.

Another aspect that was introduced was the inclusion of some online collaborative problem-solving activities. The next section presents the data related to that.

\subsection{Collaborative Problem-Solving}

\subsubsection{Changes in Approach}

Firstly, the data which illustrated the approaches used to undertake the collaborative problem-solving online and how this might differ from face-to-face problem-solving are considered. For instance, Lilly worked collaboratively with a group to gain a shared common understanding after working on the tasks individually.

Lilly: We often discussed like do you understand this, how are you reading this, how are you understanding it. We did a whole day of just concentrating on one of the slides and going through them and making sure that we were just focused on everything.

Meanwhile, Annie and her group took a different approach.

Annie: Some of us posted earlier and then others were later so it was quite a flexible way to do an activity. I thought it was quite good. And it was helpful reading through what the other three put as well. I did quite enjoy it.

She also found that it enhanced her problem-solving in relation to several aspects, particularly regarding needing to think critically and articulate her position or argument. For instance, the following were extracted from the interviews.

Annie: I think it does generate critical discussion. And it made us think. It was more practical learning with the activity you put up. It was actually using your brain with a bit more authority, with the maths. 
Annie: I think I learned more, actually, to be honest, probably more because I had to really think about it, because I haven't done this type of math for a long time as well.

\subsubsection{Influence on Reflection}

At times, this thinking was particularly reflective, both on the other's contributions, but also self-reflective.

Shelley: I think again because maybe we weren't in one room, I gave myself so much more time to think about it probably. And I would see what other people would say, and again I was in that kind of transition where I didn't feel like I had to respond to anyone immediately. I made my own timetable. So, I definitely thought about it a lot deeper than I would have had we been face-to-face.

Lilly: It was good (the Collaborative PS approach), actually it gave us a bit of time to do it. It was good having some better lead time and was helpful. So, you go away initially. Think about it. Some of these got really hard to that's why I wanted to do some collaborative stuff. You've really got to work together and get it sorted. That's why I thought it was a good way to sort of get that going. So, you're in a peer group so that it's good for confidence, but it also helps when one person explains it.

Shelley: Yeah, there's definitely a lot more opportunity to look back at either previous work you've done or read other people's work, and put the pieces together before you respond.

However, Shelley also indicated that perhaps this more considered, in-depth reflective approach stifled some intuition.

Shelley: Then I think you miss out on perhaps just going with your gut and using your intuition.

\section{Discussion}

The data were relatively cohesive around several central aspects related to the research question: In what ways did the COVID-19 lockdown affect tertiary students' mathematics education learning, collaborative problem-solving in particular?

First are considered their perspectives on the transition to eLearning experience.

The rapidity and enforced nature of the transition to eLearning was initially very disruptive to all students. The setting up of workspaces and increased complexity of their home working environment led to stress and feelings of isolation. Much of this was related to the complexity of studying at home and the related experiences [60], especially for Anna and Lilly with children and partners now integrated into the studying environment, and each having particular impacts. Although this affected the mathematics education learning experience, this impact was in effect instigated independently of the eLearning and was more a social element of the changing living conditions. It did impact on the perceptions of the learning, however, and on their ability to communicate and collaborate. Anna mentioned her enjoyment of face-to-face learning, especially with the mediating of the mathematics education learning through interacting with the other students and lecturer [8].

This was the style of learning that she was anticipating. Additionally, these concerns would not be entirely unexpected, because these students had selected a blended delivery paper with considerable face-to-face time indicated. Presumably, that suited their initial circumstances and so any change could be presumed to be problematic, let alone with the enforced lockdown into whole family bubbles and needing to continue teaching and studying completely from home. However, the diversity of student backgrounds [12] and challenges related to equitable participation [13] are aspects of digitalization of the learning generally that need to be considered in the transition to eLearning. Anna identified the 
advantage of not having to navigate the traffic and issues with parking. This is a common advantage of working from home [61].

Once the initial transition was navigated, they identified pedagogical benefits related to eLearning. One was the flexibility within the work environment when using mobile technologies. This is similar to what Calder and Murphy [62] identified with children in their classes. It introduced a greater range of workspaces such as beanbags, allowing for student preferences. Shelley also indicated that she did far more focused reading, and reflected on and processed the mathematics education ideas through thinking and making notes. Anna came to enjoy the variety of pedagogical media that including videoconferencing offered [8,14,27], and recommended that more videoconferencing meetings become a permanent feature of the paper. It also was shown to be valuable professional development learning that Shelley and Lilly identified could be applied to their future mathematics teaching, something that Ervin-Kassab [23] also contends. She also adapted her approach to learning the mathematics by working more collaboratively with her peers, in a similar manner to the findings of Gronseth et al. [21].

The data also recognized that the enhanced emphasis on eLearning improved ongoing communication between students, and between the lecturer and students. This resonates with Goddard's [24] and Nagle's [28] findings. At times, this was through an informal social medium, for example, Facebook or Messenger, enhancing and helping maintain the CoI [21]. This suggested that the combination of asynchronous communication through mobile instant messaging, and synchronous communication through videoconferencing, led to a significant social connection being established. The participants in this study indicated that these were very supportive, alleviating feelings of isolation, and in two of the cases were instrumental in them maintaining study in the papers. Interestingly, the emphasis in the informal communication changed from discussions of course content to conversations related to well-being and emotional support [63].

The use of apps in eLearning has been found to enhance mathematics problem-solving processes, with screen-casting apps advocated for increasing problem-solving and inquiry processes [8]. The findings also indicated benefits for collaborative mathematics problemsolving. They all perceived that the engagement with the social media group was beneficial. In contrast with completing a problem-solving task with an in-class group, it gave them space to make sense of and organize their thinking about the problem and the mathematics involved [32]. The use of asynchronous media had other benefits. As well as the additional time, Annie found that it was helpful to read through the input from the other students. She could draw together all the ideas, even those who contributed after her, before the videoconferencing meeting to negotiate the solution(s).

They all found that the collaborative mathematics problem-solving in the eLearning process led to a more reflective approach [15]. Shelley noted that having more time and responding after reflection led to her thinking more deeply than when she was in class. However, Shelley also indicated that this more considered, reflective approach appeared to inhibit intuitive processes. The communication aspect was perceived to be essential too, both formal and informal; to negotiate areas of uncertainty, enhancing confidence. Two of the participants particularly highlighted the critical thinking aspect of the reflections, a key element of mathematical problem-solving [5,64].

\subsection{Implications}

A key implication is that there needs to be quality support for students and teachers in the transition. Hardware (e.g., tablets), connectivity (e.g., Wi-Fi in homes), effective apps (e.g., Zoom, Seesaw) and emotional support through regular contact and empathy to individuals' circumstances are all critical in the successful transition, whether enforced again through future lockdowns, or just through a desire to embed eLearning as part of the pedagogical media in the long term. It was evident to the participants that more eLearning, once they adapted to it, brought more variety and interest to the papers. These students still wanted a face-to-face component, but more integration of digital resources 
and recommended different usages of some existing techniques. At the institutional level, providers would be wise to incorporate elements of eLearning into all face-to-face papers and make more and different tools accessible and support eLearning and emotional support for students and teachers, in any transition, to the greater use of eLearning. We would suggest that institutions incorporate eLearning platforms, such as Moodle, in all their papers and encourage lecturers to have their students form informal social media groups. These appear to not only enhance existing face-to-face papers, but would great alleviate issues related to any future enforced transitions to fully online learning. Educators experienced and proficient with eLearning found the transition easier and experienced fewer challenges [27].

In terms of communicating in collaborative mathematics problem-solving through digital pedagogical media, our findings supported those that recommended breakout rooms in Zoom (e.g., Green and Johnson-Whitt [7]), but also grouping students in other media including informal social networks, both inside and outside of class structures. For these participants, the combination of both seemed most effective. The informal social media groupings were also a forum for emotional and social support. The blend of synchronous and asynchronous learning also seemed important, with the asynchronous (e.g., Moodle discussion forums) allowing more time to better make sense of the mathematics and reflect on the problems, and the synchronous (e.g., Zoom) allowing the negotiation of shared understandings and solutions, enhancing confidence.

\subsection{Limitations}

There are limitations related to the case-study research design. Although the small number of participants limits the generalizability of the findings, their purpose was to generate rich, contextual data and therefore enhance the understanding of a situation through particular insights. In this regard, we feel that the research opened up space for understanding the experiences of tertiary students studying mathematics education that other research designs, such as large online surveys, would not have. We contend that the research also provides insights into how schools and businesses might better manage this transition if required in the future.

Another limitation is that COVID-19 is still emerging and transmuting into new variants; hence, we are making decisions and recommendations based on the situation at the time with no concrete long-term evidence. Nevertheless, while limited in this regard, we feel that the learning is still informative.

\subsection{Possible Future Research}

There is scope for further research that emerged through the analysis and examination of the findings. A larger sample, including a combination of methods such as observations and surveys, would incorporate a broader range of student perspectives and enable more reliable generalization of the influence of eLearning on collaborative mathematics problemsolving. Research into the use of formal, e.g., Moodle, and informal, e.g., Messenger, platforms incorporated into all papers, even those that are fully face-to-face, to examine the influence on engagement and understanding would be valuable. Finally, research into possible future digital eLearning tools, such as the use of augmented or virtual reality would likewise be informative and provide valuable insights into possible future permutations of eLearning in mathematics education.

Overall, we feel that the research revealed important insights into how the impact of the COVID-19 lockdown affected tertiary students' learning experiences, particularly related to communicating their algebraic thinking in mathematics education and the process of collaborative problem-solving. Importantly, it highlighted the effect of individuals' personal circumstances and sense of wellbeing, and enhanced understanding of the transition to eLearning that could apply to other educational settings, and perhaps administration and business contexts. 
Author Contributions: The authors made the following individual contributions to the paper. The conceptualization of the research study and paper, N.C.; methodology, N.C.; validation, N.C. and M.J.; formal analysis, N.C. and L.G.; investigation, N.C.; resources, N.C. and M.J.; data curation, N.C. and L.G.; writing—original draft preparation, N.C.; writing—review and editing, N.C., M.J. and L.G.; supervision, N.C.; project administration, N.C.; and funding acquisition, N.C. All authors have read and agreed to the published version of the manuscript.

Funding: This research received funding from a contestable internal University research grant.

Institutional Review Board Statement: The study was conducted according to the guidelines of the Declaration of Helsinki, and approved by the Ethics Committee of University of Waikato, Division of Education: FEDU060/20.

Informed Consent Statement: Informed consent was obtained from all subjects involved in the study.

Data Availability Statement: Data supporting the reported results are stored on a passwordprotected laptop and on the University servers.

Conflicts of Interest: The authors declare no conflict of interest.

\section{References}

1. Ferdig, R.E.; Baumgartner, E.; Hartshorne, R.; Kaplan-Rakowski, R.; Mouza, C. Teaching, Technology, and Teacher Education during the COVID-19 Pandemic: Stories from the Field; AACE-Association for the Advancement of Computing in Education: Waynesville, NC, USA, 2020.

2. Jafri, M. Teaching Mathematics with Digital Content Resource in Pakistan. A Review of the Emerging Frameworks for The Use Of Digital Technology In Mathematics Education. Bahria Univ. J. Humanit. Soc. Sci. 2020, 3, 14-38.

3. Hegedus, S.; Laborde, C.; Brady, C.; Dalton, S.; Siller, H.S.; Tabach, M.; Trgalova, J.; Moreno-Armella, L. Uses of technology in upper secondary mathematics education. In ICME-13 Topical Survey; Springer: Heidelberg/Berlin, Germany, 2016 ; p. 43.

4. Tabach, M.; Trgalová, J. Teaching mathematics in the digital era: Standards and beyond. In STEM Teachers and Teaching in the Digital Era: Professional Expectations and Advancement in the 21st Century Schools; Kolikant, Y.B., Martinovic, D., Milner-Bolotin, M., Eds.; Springer International Publishing: Cham, Switzerland, 2020; pp. 221-242.

5. Zheng, R.Z. Examining Multiple Intelligences and Digital Technologies for Enhanced Learning Opportunities; IGI Global: Hershey, PA, USA, 2019.

6. Carey, L.B.; Sadera, W.A.; Cai, Q.; Filipiak, S. Creating a community of practice for educators forced to transition to remote teaching. In Teaching, Technology, and Teacher Education during the COVID-19 Pandemic: Stories from the Field; AACE-Association for the Advancement of Computing in Education: Waynesville, NC, USA, 2020; pp. 251-255.

7. Green, J.; Johnson-Whitt, E. Through the Constructivist Lens A Vision for Preparing Pre_Service Teachers for Online Teaching; AACEAssociation for the Advancement of Computing in Education: Waynesville, NC, USA, 2020; pp. 379-385.

8. Morge, S.P. Promoting mathematics problem solving and collaboration in synchronous courses. In Teaching, Technology, and Teacher Education During the COVID-19 Pandemic: Stories from the Field; AACE-Association for the Advancement of Computing in Education: Waynesville, NC, USA, 2020; pp. 129-132.

9. Krumsvik, R.J. Teacher educators' digital competence. Scand. J. Educ. Res. 2014, 58, 269-280. [CrossRef]

10. MoE. The New Zealand Curriculum for English-Medium Teaching; Ministry of Education NZ: Wellington, New Zealand, 2007 ; p. 67.

11. Tallvid, M. Understanding teachers' reluctance to the pedagogical use of ICT in the 1:1 classroom. Educ. Inf. Technol. 2016, 21, 503-519. [CrossRef]

12. Tømte, C.E.; Fossland, T.; Aamodt, P.O.; Degn, L. Digitalisation in higher education: Mapping institutional approaches for teaching and learning. Qual. High. Educ. 2019, 25, 98-114. [CrossRef]

13. Skrobanek, J.; Jobst, S. Liquid Integration-A New Perspective on Assimilation in the Era of Super Mobilities; MGIMO University: Moscow, Russia, 2018.

14. Maher, D. Video Conferencing to Support Online Teaching and Learning. In Teaching, Technology, and Teacher Education during the COVID-19 Pandemic: Stories from the Field; AACE-Association for the Advancement of Computing in Education: Waynesville, NC, USA, 2020; pp. 91-96.

15. Gandolfi, E.; Kratcoski, A. Coping during Covid-19 Building a Community of Practice (CoP) for Technology Integration and Educational Reform in a Time of Crisis. In Teaching, Technology, and Teacher Education During the COVID-19 Pandemic: Stories from the Field; Ferdig, R.E., Baumgartner, E., Hartshorne, R., Kaplan-Rakowski, R., Mouza, C., Eds.; AACE-Association for the Advancement of Computing in Education: Waynesville, NC, USA, 2020; pp. 169-173.

16. Calder, N. Apps: Appropriate, Applicable, and Appealing? In Digital Games and Mathematics Learning: Potential, Promises and Pitfalls; Lowrie, T., Jorgensen, R., Eds.; Springer: Dordrecht, The Netherlands, 2015; pp. 233-250.

17. Barkley, E.F.; Cross, K.P.; Cross, K.P. The Case for Collaborative learning. In Collaborative Learning Techniques: A Handbook for College Faculty; John Wiley \& Sons: Hoboken, NJ, USA, 2014; pp. 15-33.

18. Walshaw, M.; Anthony, G. Policy Implementation: Integrating the Personal and the Social. Math. Teach. Educ. Dev. 2007, 8, 5-22. 
19. Carreira, S.; Jacinto, H. A Model of Mathematical Problem Solving with Technology: The Case of Marco Solving-and-Expressing Two Geometry Problems. In Mathematical Problem Solving: Current Themes, Trends, and Research; Liljedahl, P., Santos-Trigo, M., Eds.; Springer International Publishing: Cham, Switzerland, 2019; pp. 41-62.

20. Schoenfeld, A.H. Making sense of 'out loud' problem-solving protocols. J. Math. Behav. 1985, 4, 171-191.

21. Gronseth, S.; Fu, J.; Hebert, W.; Zhang, H. Connecting Learners Through Technology in COVID-19: Facilitating Pre-Service Teacher Collaboration During the Pandemic. In Teaching, Technology, and Teacher Education during the COVID-19 Pandemic: Stories from the Field; AACE-Association for the Advancement of Computing in Education: Waynesville, NC, USA, 2020 ; pp. $179-185$.

22. Hew, K.F.; Cheung, W.S. Student Participation in Online Discussions: Challenges, Solutions, and Future Research; Springer: New York, NY, USA, 2012.

23. Ervin-Kassab, L. Playing with Faculty Kassab 2020. In Teaching, Technology, and Teacher Education during the COVID-19 Pandemic: Stories from the Field; AACE-Association for the Advancement of Computing in Education: Waynesville, NC, USA, 2020; pp. $17-22$.

24. Goddard, A.R. Remote coteaching norms for teachers of English learners. In Teaching, Technology, and Teacher Education during the COVID-19 Pandemic: Stories from the Field; AACE-Association for the Advancement of Computing in Education: Waynesville, NC, USA, 2020; pp. 3-6.

25. Coleman, K.; MacDonald, A. What Are Artists and Art Educators Teaching Us About How We Can Conceive and Deliver Teacher Professional Learning Into the Future? In Teaching, Technology, and Teacher Education during the COVID-19 Pandemic: Stories from the Field; AACE-Association for the Advancement of Computing in Education: Waynesville, NC, USA, 2020; pp. 13-16.

26. Hulon, S.I.; Tucker, M.H.; Green, A.M. Virtual Professional Learning for In-Service Teachers to Support Teaching and Learning in Online Environments. In Teaching, Technology, and Teacher Education during the COVID-19 Pandemic: Stories from the Field; AACE-Association for the Advancement of Computing in Education: Waynesville, NC, USA, 2020; pp. 43-46.

27. Lindsay, L.; Whalley, R. Building Resilience in New Zealand Schools through Online Learning. In Teaching, Technology, and Teacher Education During the COVID-19 Pandemic: Stories from the Field; AACE-Association for the Advancement of Computing in Education: Waynesville, NC, USA, 2020; pp. 55-58.

28. Nagle, T. COVID Notes from the Field: Differentiation in the Digital Classroom. Georg. Educ. Res. 2020, 17, 1-3. [CrossRef]

29. Pólya, G. How to Solve It! A New Aspect of Mathematical Method; Princeton University Press: Princeton, NJ, USA, 1945.

30. Silver, H.; Strong, R.; Perini, M. Integrating learning styles and multiple intelligences. Educ. Leadersh. 1997, 55, $22-27$.

31. Szabo, Z.K.; Körtesi, P.; Guncaga, J.; Szabo, D.; Neag, R. Examples of problem-solving strategies in mathematics education supporting the sustainability of 21st-century skills. Sustainability 2020, 12, 10113. [CrossRef]

32. Holton, R. Deciding to trust, coming to believe. Australas. J. Philos. 1994, 72, 63-76. [CrossRef]

33. Bergqvist, T. How students verify conjectures: Teachers' expectations. J. Math. Teach. Educ. 2005, 8, 171-191. [CrossRef]

34. Manouchehri, A. Using interactive algebra software to support a discourse community. J. Math. Behav. 2004, 23, 37-62. [CrossRef]

35. Roschelle, J.; Teasley, S.D. The Construction of Shared Knowledge in Collaborative Problem Solving. In Computer Supported Collaborative Learning; NATO ASI Series (Series F: Computer and Systems Sciences); O'Malley, C., Ed.; Springer: Berlin/Heidelberg, Germany, 1995; pp. 69-97.

36. OECCD. PISA 2015 Assessment and Analytical Framework, revised ed.; OECD Publishing: Paris, France, 2017.

37. Zurita, G.; Nussbaum, M. Computer supported collaborative learning using wirelessly interconnected handheld computers. Comput. Educ. 2004, 42, 289-314. [CrossRef]

38. Mercer, N.; Littleton, K. Dialogue and the Development of Children's Thinking: A Sociocultural Approach; Routledge: New York, NY, USA; London, UK, 2007.

39. Ruthven, K. Linking Researching With Teaching: Towards Synergy of Scholarly and Craft Knowledge. In Handbook of International Research in Mathematics Education; Lawrence Erlbaum Associates: Mahwah, NJ, USA, 2001; pp. 593-610.

40. Bonk, C.J.; Khoo, E. Adding Some TEC-VARIETY: 100+ Activities for Motivating and Retaining Learners Online; Open World Books: Bloomington, IN, USA, 2014.

41. Calder, N. The layering of mathematical interpretations through digital media. Educ. Stud. Math. 2011, 80, 269-285. [CrossRef]

42. Falloon, G.; Khoo, E. Exploring young students' talk in iPad-supported collaborative learning environments. Comput. Educ. 2014, 77, 13-28. [CrossRef]

43. Olive, J.; Makar, K.; Hoyos, V.; Kor, L.K.; Kosheleva, O.; Strässer, R. Mathematical knowledge and practices resulting from access to digital technologies. In Mathematics Education and Technology-Rethinking the Terrain; Springer: Heidelberg/Berlin, Germany, 2010; pp. 133-177.

44. Santos-Trigo, M. Mathematical problem solving and the use of digital technologies. In Mathematical Problem Solving: Current Themes, Trends, and Research; Liljedahl, P., Santos-Trigo, M., Eds.; Springer International Publishing: Cham, Switzerland, 2019; pp. $63-89$.

45. Carreira, S. Mathematical Problem Solving Beyond School: Digital Tools and Students' Mathematical Representations. In Selected Regular Lectures from the 12th International Congress on Mathematical Education; Springer: Cham, Switzerland, 2015 ; pp. 93-113. [CrossRef]

46. Schoenfeld, A.H. Toward professional development for teachers grounded in a theory of decision making. ZDM Int. J. Math. Educ. 2011, 43, 457-469. [CrossRef] 
47. Khalil, M. Effect of GeoGebra (DGS) Aided Instructions on Grade-12 Students' Mathematical Thinking and Mathematical Achievement in Analytical Geometry; Northern University: Nowshera, Pakistan, 2016.

48. Zheng, R.Z. (Ed.) Examining Multiple Intelligences and Digital Technologies for Enhanced Learning Opportunities; IGI Global: Hershey, PA, USA, 2020.

49. Liljedahl, P.; Santos-Trigo, M. Mathematical Problem Solving: Current Themes, Trends, and Research; Springer Nature: Cham, Switzerland, 2019.

50. Zorica, M.B. Edutainment at the Higher Education as an Element for the Learning Success. In Proceedings of the EDULEARN14 Conference, Barcelona, Spain, 7-9 July 2014; pp. 4089-4097.

51. Borba, M.C.; Askar, P.; Engelbrecht, J.; Gadanidis, G.; Llinares, S.; Aguilar, M.S. Blended learning, e-learning and mobile learning in mathematics education. ZDM Math. Educ. 2016, 48, 589-610. [CrossRef]

52. Symons, D.; Pierce, R. Beyond fluency: Promoting Mathematicsal Proficiencies through Online Collaborative Problem Solving. Aust. Prim. Math. Classr. 2019, 24, 4-9.

53. Wegerif, R. Dialogic Education and Technology: Expanding the Space of Learning; Springer Science \& Business Media: Heidelberg/Berlin, Germany, 2007; Volume 7.

54. Bernacki, M.L.; Greene, J.A.; Crompton, H. Mobile technology, learning, and achievement: Advances in understanding and measuring the role of mobile technology in education. Contemp. Educ. Psychol. 2020, 60, 101827. [CrossRef]

55. Hartshorne, R.; Baumgartner, E.; Kaplan-rakowski, R.; Mouza, C.; Ferdig, R.E. Preservice and inservice professional development during the COVID-19 pandemic. J. Technol. Teach. Educ. 2020, 28, 137-147.

56. Yin, R.K. Case Study Research and Applications: Design and Methods, 5th ed.; Sage Publications: Los Angeles, CA, USA, 2014.

57. Creswell, J.W.; Creswell, J.D. Research Design: Qualitative, Quantitative, and Mixed Methods Approaches, 5th ed.; Sage Publications: Los Angeles, CA, USA, 2018.

58. Crotty, M.; Crotty, M.F. The Foundations of Social Research: Meaning and Perspective in the Research Process; Sage: Los Angeles, CA, USA, 1998.

59. Braun, V.; Clarke, V. Using thematic analysis in psychology. Qual. Res. Psychol. 2006, 3, 77-101. [CrossRef]

60. Kong, Q. Practical Exploration of Home Study Guidance for Students during the COVID-19 Pandemic: A Case Study of Hangzhou Liuxia Elementary School in Zhejiang Province, China. Sci. Insights Educ. Front. 2020, 5, 557-561. [CrossRef]

61. Ipsen, C.; van Veldhoven, M.; Kirchner, K.; Hansen, J.P. Six Key Advantages and Disadvantages of Working from Home in Europe during COVID-19. Int. J. Environ. Res. Public Health 2021, 18, 1826. [CrossRef] [PubMed]

62. Calder, N.; Murphy, C. Reshaping the learning experience through apps: Affordances. In Uses of Technology in Primary and Secondary Mathematics Education; Springer: Heidelberg/Berlin, Germany, 2018; pp. 145-159.

63. Johnson, C.; Merrick, B. Enabling Music Students' Well-Being through Regular Zoom Cohort Chats during the Covid-19 Crises. In Teaching, Technology, and Teacher Education during the COVID-19 Pandemic: Stories from the Field; AACE-Association for the Advancement of Computing in Education: Waynesville, NC, USA, 2020; pp. 261-264.

64. Lynch-Arroyo, R.; Asing-Cashman, J. Using Edutainment to Facilitate Mathematical Thinking and Learning: An Exploratory Study. J. Math. Educ. 2016, 9, 37-52. 